\section{Notes on the distribution of Maesa velutina Mez (Myrsinaceae) - a rare and endemic plant from India}

\section{M.M. Sardesai ${ }^{1} \&$ S.R. Yadav ${ }^{2}$}

\author{
${ }^{1}$ Department of Botany, Dr. Babasaheb Ambedkar Marathwada \\ University, Aurangabad, Maharashtra 431004, India \\ ${ }^{2}$ Department of Botany, Shivaji University, Kolhapur, \\ Maharashtra 416004, India \\ Email: ${ }^{1}$ sardesaimm@gmail.com (corresponding author) \\ ${ }^{2}$ sryadavdu@rediffmail.com
}

While working on the floristics of Kolhapur District during 1999, some specimens of Maesa were collected. They were tentatively identified as $M$. indica var. dubia. However, on comparison with the herbarium specimens of related species deposited with the Botanical Survey of India, Western Circle, Pune (BSI) (MMS 1267) (Image 1), it became clear, that specimens collected by us differed from $M$. indica var. dubia by a number of characters.

The publication by Kumar et al. (2008), wherein the authors have reinvestigated the identity of the species, enabled us to place the specimens collected by us correctly as M. velutina Mez.

Earlier, the taxon was known only from three gatherings. Later, two additional populations were located, one in Kerala State and the other in Karnataka State (Kumar et al. 2008). The present report confirms the occurrence of this taxon in Maharashtra State (Image 2).

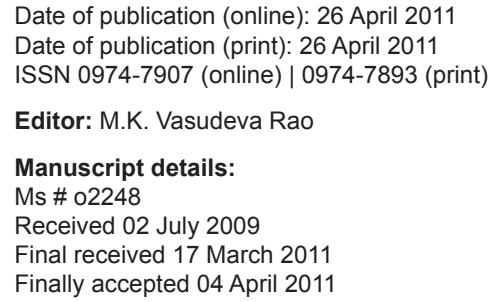

Citation: Sardesai, M.M. \& S.R. Yadav (2011). Notes on the distribution of Maesa velutina Mez (Myrsinaceae) - a rare and endemic plant from India. Journal of Threatened Taxa 3(4): 1735-1736.

Copyright: ( $)$ M.M. Sardesai \& S.R. Yadav 2011. Creative Commons Attribution 3.0 Unported License. JoTT allows unrestricted use of this article in any medium for non-profit purposes, reproduction and distribution by providing adequate credit to the authors and the source of publication.

Acknowledgements: The authors are thankful to Dr. E.S. Santhosh Kumar of Tropical Botanic Garden and Research Institute, Palode, Thiruvanantpuram, Kerala for confirming of identity of the taxon.

OPEN ACCESS | FREE DOWNLOAD
Specimens 20.iv.1999,

examined: Radhanagari,

Kolhapur District, Maharashtra State, India, coll. Milind M.

Sardesai, specimens are deposited in the Herbarium of the Department of Botany, Shivaji University, Kolhapur (MMS 1267).

Maesa velutina Mez in Engl., Pflazenr. IV, 236: 35. 1902; T. Cooke, Fl. Pres. Bombay 2:142.1958 (Repr.); M.R. Almeida F1. Maharashtra 3A: 164. 2001; Londhe in N.P. Singh et al. Fl. Maharashtra St., Dicot. 2: 289. 2002; Kumar et al. Rheedea 18 (1): 39-42. 2008.

Large shrubs with young branches, ferruginous hairy. Leaves elliptic, margin serrate, densely ferruginous hairy, glabrous above except along the veins, densely pilose beneath. Inflorescence axillary or lateral raceme.

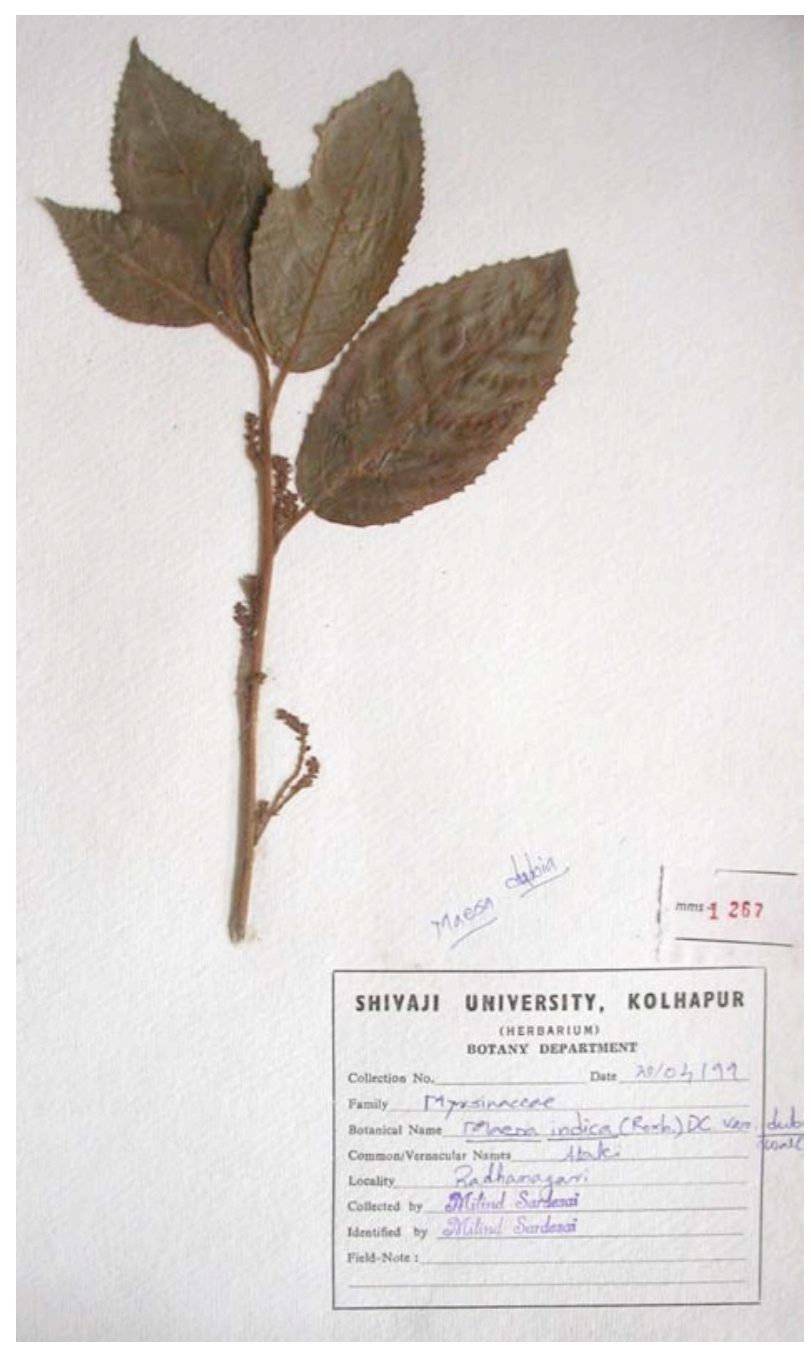

Image 1. Herbarium of Maesa velutina 


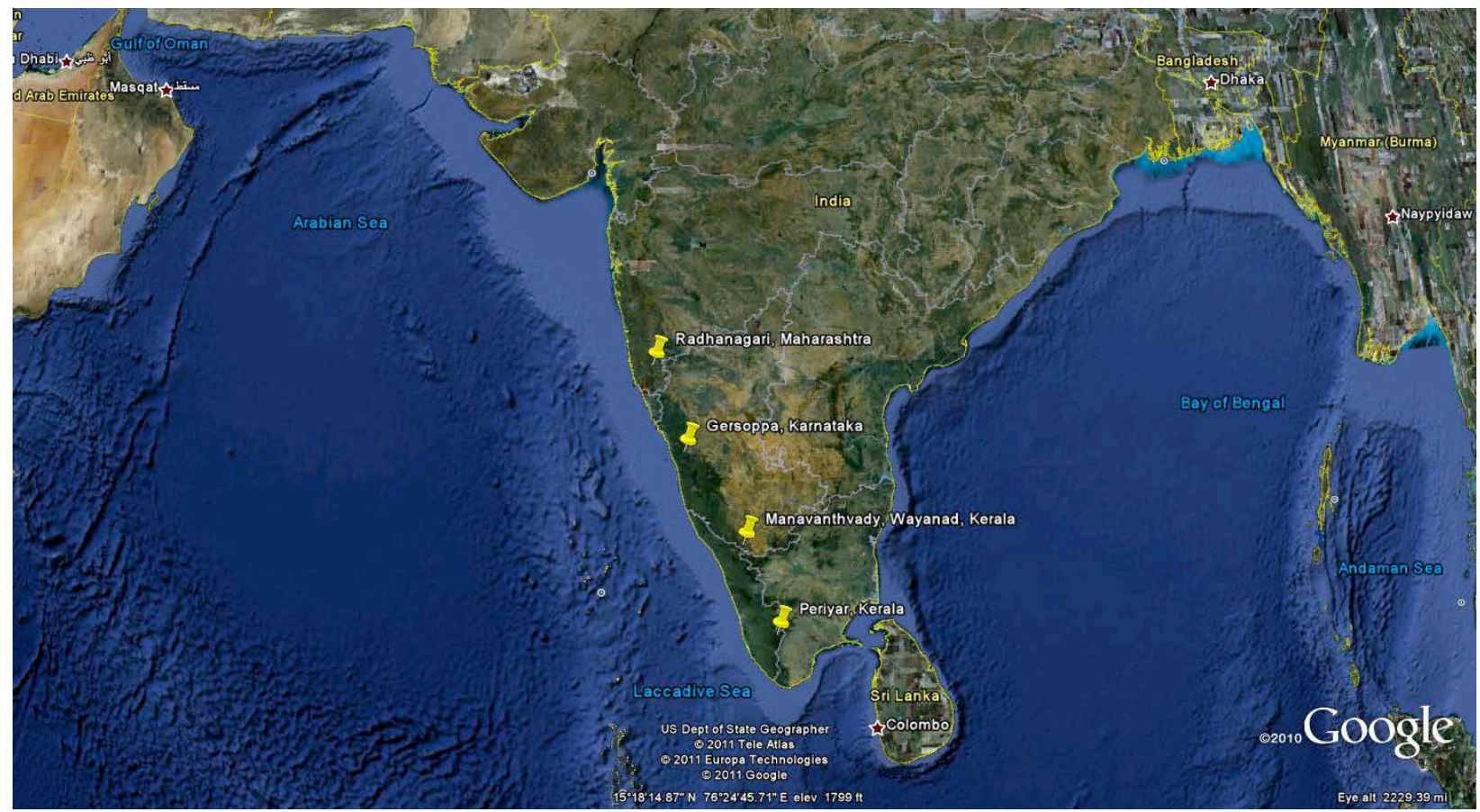

Image 2. Distribution of Maesa velutina Mez in Peninsular India

Flowering and Fruiting: December-May

Habitat: It grows at an altitude of $900 \mathrm{~m}$ altitude along a stream bank in the semievergreen forests of Radhanagari forest range. Common associates include Boehmeria glomerulifera Miq., Callicarpa tomentosa (L.) Murr., Elaeocarpus serratus L., Euonymus indicus Heyne ex Wall., Ficus racemosa L., Garcinia talbotii Raiz. ex Sant., Glochidion ellipticum Wight, Holigarna grahamii (Wight) Kurz., Homalium ceylanicum (Gardn.) Benth., Hydnocarpus pentandra (Buch.-Ham.) Oken, Knema attenuata (Wall. ex Hook. f. \& Thoms.) Warb., Mackenziea integrifolia (Dalz.) Bremek., Meiogyne pannosa (Dalz.) Sinclair, Nilgirianthus heyneanus (Nees) Bremek., Nothapodytes nimmoniana (Grah.) Mabb. and Symplocos cochinchinensis (Lour.) S. Moore subsp. laurina. (Retz.) Nooteb.

Distribution: India (Western Ghats: Kerala, Karnataka and Maharashtra).

\section{Remarks}

Cooke (1901-08) reported two species and a variety of Maesa. However, he had doubtfully included $M$. velutina, stating that: "Of this I have seen no specimens; there are none in herbarium kew. According to Mez the plant grows in Bombay Presidency, Dr. Gibson's specimens are in Herbarium Leiden.

Almeida (2001) included this taxon for the Flora of Maharashtra based on Cooke's report. Therefore, the present paper reports the first authentic collection in recent years and confirms the distribution of $M$. velutina in the state of Maharashtra.

\section{REFERENCES}

Almeida, M.R. (2001). Flora of Maharashtra-Vol. 3A. St. Xaviers College, Mumbai, 300pp.

Cooke, T. (1901-08). The Flora of the Presidency of BombayVol. II. London. (B.S.I. Reprint, 1958), Culcutta.

Kumar, E.S.S., K. Radhakrishnan, C. Kunhaknan, J.F. Veldkamp \& C.N. Mohanan (2008). Rediscovery of Maesa velutina Mez. (Maesaceae/Myrsinaceae): An endemic and endangered species of Western Ghats, India. Rheedea 18(1): 39-42.

Londhe, A.N. (2002). Family Myrsinaceae, pp. 285-290. In: Singh, N.P., P. Lakshminarasimhan, S. Karthikeyan \& P.V. Prasanna (eds). Flora of Maharashtra State, DicotyledonesVol 2. Botanical Survey of India, Calcutta. 